\title{
Numerical Relay: Influenced by and Accessing the Power Quality
}

\author{
Ruth P.S. Leao, Giovanni C. Barroso, Nelber X. Melo, \\ Raimundo F. Sampaio, Janaína A. Barbosa and Fernando L.M. Antunes \\ Federal University of Ceara - UFC \\ Brazil
}

\section{Introduction}

With the latest technological advances in the area of monitoring, protection and control systems, together with the availability of digital communication technologies, the power utilities have been requested to deliver a greater amount of specific information to a broad range of users such as customers, grid operators, regulation agencies and market operators.

The power systems make use of permanently installed, integrated, measuring devices that collect, measure, and evaluate one or more characteristic parameters with the intention of automatically determining and reporting the status of the monitored system (Mackrell et al, 2010). Information provided by the real-time monitoring system enables the right decisions to be made for improving security, reliability and performance of the networks.

Relay devices form a major part of all monitoring, protection and control systems. These protection relays are multifunctional devices, primarily employed to provide related equipment and system protection, and more recently, they have been adapted to assist the power quality evaluation of power systems.

Power quality defines an acceptable set of limits that allow power systems and ultimately the equipment-user to operate within their intended manner with efficiency and expected life span. Power quality deviation refers to a wide variety of electromagnetic phenomena that characterizes the voltage and current at a given time and at a given location on the power system (IEEE Std. 1159, 1995). An electromagnetic phenomenon is a disturbance that may cause variation on voltage and current rms, frequency and waveform that degrade the performance of a device, equipment, process or system.

Sometimes power quality can be affected by transient phenomena such as system fault occurrence such as voltage interruption, voltage sag and voltage swell. The protective relays are designed to operate reliably when there are faults in the power system. The relay device must trip on detection of any fault condition and must not trip during normal operating conditions. When the fault is cleared by a relay device, quite often the supply voltage will be restored automatically to its normal operating level. The relay can therefore contribute to restoring the voltage quality of the power system. Protection relaying is primary concerned with clearing faults while power quality is concerned with the delivery of reliable power to defined quality standards (Cease and Kunsman, 2003). 
The modern multifunction digital relays are able to measure and register parameter values (currents and voltages) that are useful to the power quality assessment. The disturbances registered by the digital relays can be assessed in order to characterize the events and their severity, in terms of magnitude, duration, and the frequency of occurrence. The digital relay, equipped with advanced digital processing and high density memory chips are able therefore to concurrent performance of protection and quality analysis functions.

The protective relays, however, are among the devices that may suffer from the disturbances in the power system. When the quality of power is poor, protective relays can have problems making the correct decisions on whether to trip or not. Some power quality related phenomena may cause incorrect protection system operations. This is because the poor power quality conditions cause the relay to register erroneous input values, and for that reason, it acts erroneously. The opposite situation is also possible whereby the relay does not trip when it should, due to the poor power quality (Zamora et al, 2004). The sensitivity and the immunity of the relays are evaluated through tests performed according to international standards like IEC 60255-11 and IEC 61000-4-11.

This chapter deals with the relationship between power quality and protection relays. As the protection relays are used to assess power quality, they may suffer influence from the quality of supply. The objective of this chapter is to evaluate the impact of power disturbances upon protection relay devices. The responses of the relay to specific disturbances are evaluated and the immunity of the device is presented.

To access the power quality of a site, the protection relays can provide useful information that can be quantified by using appropriate power quality indices. This chapter aims also to assess the power quality from information provided by the protection relays.

The chapter is organized as follows section two provides an overview about the common disturbances accountable for degrading the power quality, the importance of power quality monitoring and some indices to quantify the severity of the disturbances; section three discusses issues concerning numerical relays, the influence of the power quality on their performance, and the relay responses to tests performed according to international standards. The application of numerical relays for evaluating the power quality is also included within this section; section four presents the latest advances on wide area monitoring protection and control which are revolutionizing the way state estimation is being performed; finally, the conclusions are given in the fifth section.

\section{Overview of power quality}

Power Quality is a technical term that has practical implications on the performance and productivity of end-user equipment. It can be considered as power that does not impair the operation of a customer's equipment. A power quality problem is any occurrence that manifests itself in voltage, current, or frequency deviation that results in failure or misoperation of customer equipment. If the quality of power is inadequate for those needs, then the quality is lacking.

Power quality disturbances that are common in a power system include: voltage sags, voltage swells, short-term interruptions, transients, voltage unbalance, harmonics, and voltage fluctuations.

Voltage Sag is defined as a rapid short-term decrease in voltage. As with sags, swells are usually associated with system fault conditions, but they are not as common as voltage sags. One way that a swell can occur is from the temporary voltage rise on the unfaulted phases during a single line-to-ground fault. 
Voltage Swell is defined as a rapid short-term increase in voltage typically caused by the switching off bank of capacitors and large block of loads.

Voltage Interruption is the disappearance of the supply voltage on one or more phases. When the interruption is longer than $1 \mathrm{~min}$, it is considered as sustained interruption. Interruptions can be caused by faults, control malfunctions, or equipment failures.

Transient is a sudden non-power frequency change in the steady-state condition of voltage or current, or both. When it is unidirectional in polarity (either positive or negative) it is defined as an impulsive transient, otherwise, when both polarities are included, it is considered as an oscillatory transient.

Voltage Unbalance is characterized by any differences that exist in the three phase voltage magnitude or any phase shift in the 120 degree separation between the three phases. Causes of voltage unbalance include unequal impedances of three-phase transmission and distribution system lines, large and/or unequal distribution of single-phase loads, phase-tophase loads and unbalanced three-phase loads.

Harmonics are sinusoidal voltages or currents having frequencies that are integer multiples of the frequency at which the supply system is designed to operate. Harmonics combine with the fundamental voltage or current, and produce waveform distortion (IEEE 1159, 1997).

Voltage Fluctuation is defined as a series of rms voltage changes or a cyclical variation of the voltage waveform envelope. The primary cause of voltage fluctuations is the time variability of the reactive power component of variable loads. Such loads include arc furnaces, rolling mill drives, and main winders - all of which are loads with a high rate of change of power with respect to the short-circuit capacity at the point of common coupling.

Flicker is the periodic change in the instantaneous light output of a light source caused by fluctuation of the supply voltage. Flicker is a symptom of voltage fluctuation which are typically caused by the use of large fluctuating loads, i.e. loads that have rapidly fluctuating active and reactive power demand. The increased use of high frequency electronic ballasts has greatly decreased the amount of flicker present in the indoor environment.

While power disturbances occur on all electrical systems, the sensitivity of today's electronics makes them more susceptible to them. Improvement of power quality has a positive impact on sustained profitability of the distribution utility on the one hand and customer satisfaction on the other.

\subsection{Power quality monitoring}

Power quality monitoring is necessary to characterize electromagnetic phenomena at a particular location on an electric power circuit. There are two main reasons for making power quality measurements: plant investigations in order to solve specific problems in an installation; and, utility measurements to obtain the general power quality levels in any part of the network.

Power quality monitors are intended to give all necessary information about significant power quality disturbances over a long period, varying from weeks to months. These instruments have to be able to identify and record the characteristics of many types of disturbances occurring on a timescale of microseconds (transients) to hours (steady state voltage variations). Fast transients require high sample rate analogue-to-digital converters (eg 1-4 MHz) giving a large data throughput. Operating over a long timescale this gives an enormous amount of data to be handled. These instruments must either record very little of the data handled or have large storage facilities (eg hard disk) or have the ability to send the 
data to a storage facility by means of a modem or similar communication method. To prevent overloading of memory with discrete event type disturbances, monitors have adjustable thresholds which determine the level at which a disturbance is recorded (Gosbell, 2002).

The IEC 61000-4-30 provides common requirements for measurement devices to ensure that analyzers from different manufacturers give the same results for power quality parameters in $50 / 60 \mathrm{~Hz}$ ac power supply systems. This standard ensures that different power quality instruments use the same definitions and measurement techniques, for various power quality parameters, which may take the form of overvoltages and undervoltages, interruptions, sags/dips, swells, frequency, harmonics, phase imbalance, voltage fluctuation, etc. The basic aim of this document is to define measurement methods that will make it possible to obtain reliable, repeatable and comparable results independently of the power quality meter manufacturer. The standard does not provide information about instrumentation design. This kind of information is covered by other standards such as IEC 61000-4-7 and IEC 61000-4-15 (Munõz, 2007).

Power quality instrumentation should not only have good hardware architecture, but also powerful software that permits the measured data to be managed and analyzed.

\subsection{Power quality indices}

There is an increasing need for performance criteria to assess the quality of the power supplied. Several power quality indices have been proposed to assess the severity of phenomena such as flicker, harmonic content, voltage unbalance, etc in order to analyze the system performance. The quality of the voltage supply, which is a common concern of the power utilities, must be trustworthy and able to supply simple indices in order to provide answers and to settle questions and disputes concerning the quality of supply, and to better address the required investments. This section is concerned with investigating the joint treatment for signal analysis based on both the time and the frequency domains.

To calculate the indices, samples of the measured voltage are used. The voltage signal is recorded with a given sampling rate and resolution. The sampling rate or sampling frequency defines the number of samples per second (or per other unit) taken from a continuous signal to make a discrete signal. From the sampling theorem, it is known that if lower sampling rates are used, the original signal's information may not be completely recoverable from the sampled signal. The resolution is a function of the ability of an instrument to read smaller divisions of a quantity. The voltage resolution can be expressed in bits or volts.

\subsubsection{Steady state voltage variation}

The rms value is defined as the square root of the arithmetic mean of the squares of the instantaneous values of a quantity taken over a specified time interval and a specified bandwidth. The basic measurement time interval for parameter magnitudes shall be a 10cycle time interval for a $50 \mathrm{~Hz}$ power system or 12-cycle time interval for a $60 \mathrm{~Hz}$ power system. The 10/12-cycle values are then aggregated to determine the average rms value every 10 minutes.

In a non-sinusoidal condition, the true rms voltage is evaluated by

$$
V_{r m s}=\sqrt{\sum_{h=0}^{N} V_{h}^{2}}
$$


where $V_{h}$ denotes the rms voltage of order $h$, and $N$, the maximum number of harmonics. The current true rms is derived similarly.

\subsubsection{Phase displacements between corresponding fundamental voltage and current}

To reflect the utilization of the power transferred in a non-sinusoidal and unbalanced condition, Munõz (2007) proposes a new power factor designated as the Orthogonal Current Factor, evaluated by

$$
O C F=\frac{I_{a 1} \operatorname{sen} \varphi_{a 1}+I_{b 1} \operatorname{sen} \varphi_{b 1}+I_{c 1} \operatorname{sen} \varphi_{c 1}}{I_{a 1}+I_{b 1}+I_{c 1}}
$$

where $I_{a 1}, I_{b 1}$ and $I_{c 1}$ denote the rms values of the phase currents at the fundamental frequency and $\varphi_{a 1}, \varphi_{b 1}$ and $\varphi_{c 1}$ denote the phase differences between the fundamental frequency components of the corresponding phase voltages and currents.

\subsubsection{Flicker}

The light flicker indices (Pst, Plt), as defined in IEC 61000-4-15, are a measure of perceived light flicker. The short-term flicker index Pst is a statistical quantification of perceived light flicker based on the measurement of source-voltage fluctuations. A Pst value greater than, or equal to 1, causes an irritability for people exposed to light flicker. The long-term flicker index Plt is a function of the Pst index.

\subsubsection{System-frequency variation}

Frequency deviation is due to an imbalance between generation and consumption in power systems. With the increasing number of distributed generation based on renewable resources, the distribution systems can experience frequency variations due to source intermittency, load variations and equipment malfunctions.

In order to characterize the power system frequency under normal operating conditions, the following procedures are applied. The Relative Frequency Deviation RFD can be defined as a difference between the real frequency value, $f$, and the rated frequency value, $f_{r}$, relative to $f_{r}(50 \mathrm{~Hz}$ or $60 \mathrm{~Hz})$.

$$
R F D=\frac{\Delta f}{f_{r}}=\frac{f-f_{r}}{f_{r}}
$$

The integral deviation during the day is evaluated as (Albert et al, 2008)

$$
I_{f}=\int_{0}^{24} \Delta f \cdot d t
$$

Normally, the frequency is measured every 10s. As power frequency may change within the 10s time interval, the number of cycles may not be an integer number. The fundamental frequency output is the ratio of the number of integral cycles counted during the 10s time interval, divided by the cumulative duration of the integer cycles. The evaluation of system frequency quality relies on the following procedure (Albert et al, 2008):

i. Monitoring the duration $t_{m}$ over a stated time interval (one day or one week), based on the data obtained on 10s measuring windows; 
ii. Determination of the number of 10 s intervals $\mathrm{N}$ in which the supply voltage had no deviation larger than a specified percentage as given from the contracted voltage;

iii. Determination of the number of 10 s intervals $N_{1}$ in which the frequency differs by more than $0.5 \mathrm{~Hz}$ from the rated value while the voltage is within the percentage of the contracted voltage;

iv. Determination of the number of 10 s intervals $\mathrm{N}_{2}$ in which the frequency is below the lower frequency or over the upper frequency permitted by contract while the voltage is within the percentage of the contracted voltage;

v. Checking conditions $\mathrm{N}_{1} / \mathrm{N} \leq 0.05$ and $\mathrm{N}_{2}=0$.

\subsubsection{Unbalance}

The simpler definition of Unbalance Factor (UF) for everyday applications is the IEEE definition, which applies to phase-to-phase voltage measurements only and involves three steps (Gosbell, 2002):

i. Calculate $\mathrm{V}_{\mathrm{avg}}$, the average phase-to-phase voltage;

ii Calculate $\Delta \mathrm{V}_{\max }$ maximum deviation of the phase-to-phase voltages from the average calculated in (i) above;

iii Then $\mathrm{UF}=\Delta \mathrm{V}_{\max } / \mathrm{V}_{\text {avg }}$.

The index can be expressed as,

$$
U F=\frac{\text { Maximum deviation from mean of }\left\{V_{a b}, V_{b c}, V_{c a}\right\}}{\text { Mean of }\left\{V_{a b}, V_{b c}, V_{c a}\right\}}
$$

According to IEC 61000-4-30 (2008), the supply voltage unbalance is evaluated using the method of symmetrical components. The negative sequence ratio $v_{2}$ and the zero sequence ratio $v_{0}$, expressed as a percentage, are evaluated by

$$
\begin{aligned}
& v_{2}=\frac{V_{2}}{V_{1}} \times 100 \\
& v_{0}=\frac{V_{0}}{V_{1}} \times 100
\end{aligned}
$$

where $V_{1}, V_{2}$ and $V_{0}$ are positive, negative and zero sequence voltages respectively. The current unbalance is derived similarly.

The negative sequence unbalance and zero sequence unbalance provide more precise and more directly useful values than the algorithms that use only the rms values to calculate unbalance. The zero sequence unbalance by definition is zero when phase-to-phase voltages are measured. However, the phase-to-neutral or phase-to-earth voltages may still contain the zero sequence component in that case IEC 61000-4-30 (2008).

Munõz (2007) proposes another unbalance index in his book using the concept of equivalent negative sequence voltage expressed as

$$
V_{e}^{2}=\left(V^{+}\right)^{2}+\left(V^{-}\right)^{2}+\left(V^{0}\right)^{2}
$$

where $V^{+}, V^{-}$and $V^{0}$ denotes the positive, negative and zero sequence voltage. 
The voltage unbalance factor VUF is then evaluated by:

$$
V U F=\frac{\sqrt{V_{e}^{2}-\left(V^{+}\right)^{2}}}{V_{e}}
$$

For balanced three-phase voltages $V_{\mathrm{e}}=V^{+}$and $V U F$ becomes zero. Identical considerations apply to the three-phase currents where $V$ is exchanged by $I$.

\subsubsection{Harmonics}

Harmonic distortion gives a waveform which is non-sinusoidal and repetitive. The total harmonic distortion of the voltage $V T D H$ for single-phase and balanced three-phase systems is defined as

$$
V T D H=\frac{\sqrt{\sum_{h \neq 1} V_{h}^{2}}}{V_{1}}
$$

where $V_{h}$ denotes rms values and 1 and $h$ denotes the fundamental and the harmonic order respectively.

To unbalanced three-phase systems, a single equivalent harmonic rms voltage $V_{e H}$ is defined as

$$
V_{e H}^{2}=\sum_{h \neq 1} \frac{V_{a, h}^{2}+V_{b, h}^{2}+V_{c, h}^{2}}{3}
$$

Thus, the total harmonic distortion of the voltage $V T D H$ for a three-phase unbalanced system is given by

$$
V T H D=\frac{V_{e H}}{V_{e 1}}
$$

The total harmonic distortion of the current is derived similarly.

\subsubsection{Voltage sags, swells and interruptions}

Voltage variations of a time greater than 0.5 cycles of the power frequency but less than or equal to 1 minute is a major concern when considering the susceptibility of industrial processes based on computers, programmable logic controllers, adjustable speed drives, starters, contactors, etc. Power quality events, referred to as voltage sags, swells and interruptions, or as generally called short-duration voltage variations, are among the most critical events for power utilities. Results of surveys have shown that most of the power quality disturbances are caused by short-duration voltage variation under 1s (Colaço et al, 2008).

To evaluate the grid performance for three-phase voltage sags, a set of indices has been proposed by Thallam and Heydt (2000). The electric power acceptability curves are an empirical set of curves that represent the intensity and duration of bus voltage disturbances. Alternative indices for the assessment of voltage sags, such as voltage sag energy, were proposed.

With the voltage samples captured on each channel of a measuring instrument for each event the rms voltage versus time curve can be plotted. According to the IEC 61000-4-30, the 
rms voltage of a short-term voltage variation is found by taking the voltage measured over one cycle of the power-system frequency and refreshed each half-cycle (IEC 61000-4-30, 2008), as evaluated by

$$
V_{r m s}(n)=\sqrt{\frac{1}{N} \sum_{k=1+n \frac{N}{2}}^{\left(\frac{n}{2}+1\right) N}[v(k)]^{2}}
$$

with $N$ the number of samples in one cycle, referred to as the window length, $v(k)$ the voltage sample $k$, and $V_{r m s}(n)$ the rms voltage for multiple windows. The first value of $V_{r m s}(0)$ is calculated over the samples $\mathrm{k}=(1, N)$, the next one over the samples $\left(1 / 2 N+1,1 \frac{1 / 2 N}{2}\right)$ (Bollen, Sabin, Thallan, 2003). This rms voltage value may be a phase-to-phase value or a phase-to-neutral value.

The characteristics of the event are then defined for each channel, i.e., each voltage phase. It is recognized that both voltage magnitude and duration of an event in all three phases should be considered to derive a meaningful voltage variation index (Thallan and Heydt, 2000).

The magnitude of voltage sag, swell and interruption events are defined as the remaining or residual voltage, which is measured in each channel during the event (IEC 61000-4-30, 2008). The residual voltage is the lowest rms voltage for voltage sags and short interruptions and the highest rms voltage for a swell.

In order to estimate the duration of a short-term voltage variation, some voltage threshold are considered as reference values. The duration of a short-term voltage variation is given by the time range that the reference voltage is surpassed. The typical reference values for voltage sags, swells and interruptions are $0.9 \mathrm{pu}, 0.1 \mathrm{pu}$ and $1.1 \mathrm{pu}$ in $\mathrm{rms}$ voltage, respectively. The voltage threshold is specified with the purpose of detecting the start and the end of a short-term voltage variation. On polyphase systems, a sag begins when the $V_{\text {rms }}$ voltage of one or more channels is below the sag threshold and ends when the $V_{\text {rms }}$ voltage on all measured channels is equal to, or above, the sag threshold. On polyphase systems, a swell begins when the $V_{r m s}$ voltage of one or more channels is above the swell threshold and ends when the $V_{r m s}$ voltage on all measured channels is equal to, or below, the swell threshold. On polyphase systems, a voltage interruption begins when the $V_{r m s}$ voltages of all channels fall below the voltage interruption threshold and ends when the $V_{\text {rms }}$ voltage on any one channel is equal to, or greater than, the voltage interruption threshold. The duration of a short-term voltage variation is the time difference between the beginning and the end of the event (IEC 61000-4-30, 2008).

The magnitude and duration of each event are used to calculate the single-event indices. In the following, two sorts of indices are considered. The first class of index aims to reflect the energy delivered to the load and the second one the severity of an event against a given power acceptability curve.

\section{A. Energy related indices}

Voltage swells, sags or short interruptions events at the load terminals will have impact, either because excess of energy is delivered during an occurrence of swell or some energy is not delivered to the load in the event of voltage sag or interruption. The impact depends on how much excess of energy is delivered or how much is not delivered. 
The lost energy in a sag event and short interruption event is calculated as (Bollen, Sabin and Thallan, 2003)

$$
E_{V S}=\left(1-V_{p u}^{2}\right) \times t
$$

where $t$ is the duration and $V_{\text {pu }}$ the retained voltage of the event.

The index dimension is time, and as such, when calculating the lost energy in a sag event, the index can be interpreted as the duration of an interruption leading to the same loss of energy for an impedance load as the voltage sag (Bollen, Sabin and Thallan, 2003).

The index $E_{V S}$, when applied to measure voltage swells, becomes

$$
E_{V S W}=\left(V_{p u}^{2}-1\right) \times t
$$

For three-phase calculation, the related energy for all three phases will be added. Equations (16) and (17) represent the three-phase energy indices for short-duration undervoltages and overvoltages, respectively, where $t_{i}$ is the phase event duration.

$$
\begin{aligned}
E_{V S} & =E_{V S, a}+E_{V S, b}+E_{V S, c} \\
& =\left(1-V_{p u, a}^{2}\right) \cdot t_{a}+\left(1-V_{p u, b}^{2}\right) \cdot t_{b}+\left(1-V_{p u, c}^{2}\right) \cdot t_{c} \\
E_{V S W} & =E_{V S W, a}+E_{V S W, b}+E_{V S W, c} \\
& =\left(V_{p u, a}^{2}-1\right) \cdot t_{a}+\left(V_{p u, b}^{2}-1\right) \cdot t_{b}+\left(V_{p u, c}^{2}-1\right) \cdot t_{c}
\end{aligned}
$$

When any of the three-phase voltages do not violate the reference voltage level, the corresponding event duration is nil.

The indices $E_{V S}$ and $E_{V S W}$ measure the characteristic of single events. The site indices are calculated from the single-event indices of all events measured during a certain period of time. The site indices are used for evaluation of the compatibility between the electric power source and the load, and it can be used to assist the mitigation procedures. They are also used to inform the consumers about the quality of the local supply voltage.

The site-energy index (SEI) is the sum of the energy indices for all qualified events measured at a given site during a given period. The $S E I$ is computed as

$$
S E I=\sum_{i=1}^{n} E_{V S}(i)
$$

where $i$ is the event number and $n$ the total number of events in a site.

System indices can also be evaluated by taking the average value of the site indices. They are defined as the ratio of the sum of all the site indices within a given region, in a given period. A region can be understood as the utility grid, the network of a given voltage level, a state or province or a country. The system indices can be used to evaluate the system performance and to compare year-to-year variations (Bollen, Salin and Thallan, 2003).

$$
S E I_{\text {sistema }}=\frac{1}{N} \sum_{i=1}^{N} \operatorname{SEI}(i)
$$

where $i$ is the site number and $N$ is the total number of sites. 


\section{B. Event-severity index based on power acceptability curves}

The power acceptability curves so-called CBEMA (Computer Business Equipment Manufacturers Association), ITIC (Information Technology Industry Council), and SEMI (Semiconductor Equipment and Materials International group) are commonly used curves to identify the acceptability of the service supply. When disturbances occur, one may plot the disturbance on the curve, and readily identify whether loss of load is expected. This information may be used to identify whether the distribution system design is adequate, whether power quality enhancement equipment is needed, and whether load vulnerability needs to be lessened (Thallan, Heydt, 2000).

The power acceptability curves may be used as references curves to identify the severity of short-term voltage variations. The event-severity index can be calculated for voltage sags and short interruptions from

$$
S_{e}=\frac{1-V_{p u}}{1-V_{\text {curva }}(d)}
$$

$V_{p u}$ is the least rms voltage in pu in any of the three phases during the event, $\mathrm{d}$ is the event duration, and $V_{\text {curva }}(d)$ is the retained voltage of the reference curve to the same duration $d$. The algorithm for calculating the event-severity index $S_{e}$ by comparing these values with the SEMI curve is given in Table I.

\begin{tabular}{|c|c|c|}
\hline Magnitude & Duration & $\mathrm{S}_{\mathrm{e}}$ \\
\hline $0,0 \mathrm{pu}$ & $\mathrm{d} \leq 20 \mathrm{~ms}$ & $\mathrm{~S}_{\mathrm{e}}=1-\mathrm{V}$ \\
$0,5 \mathrm{pu}$ & $20 \mathrm{~ms}<\mathrm{d} \leq 200 \mathrm{~ms}$ & $\mathrm{~S}_{\mathrm{e}}=2(1-\mathrm{V})$ \\
$0,7 \mathrm{pu}$ & $200 \mathrm{~ms}<\mathrm{d} \leq 500 \mathrm{~ms}$ & $\mathrm{~S}_{\mathrm{e}}=3,3(1-\mathrm{V})$ \\
$0,8 \mathrm{pu}$ & $500 \mathrm{~ms}<\mathrm{d} \leq 10 \mathrm{~s}$ & $\mathrm{~S}_{\mathrm{e}}=5(1-\mathrm{V})$ \\
$0,9 \mathrm{pu}$ & $\mathrm{d}>10 \mathrm{~s}$ & $\mathrm{~S}_{\mathrm{e}}=10(1-\mathrm{V})$ \\
\hline
\end{tabular}

Table 1. The Event-Severity Index Definition for the SEMI Curve

As the voltage sag duration increases and the retained voltage decreases, the event-severity index becomes larger. For severity indices equal or smaller than one, it means that the reported voltage sags and short interruptions severities are in the acceptable operation region of the SEMI curve. On the other hand, when the severity indices are greater than one, it denotes that there is no compliance to the SEMI curve.

\subsubsection{Composite power quality Indices}

Practical composite indices of power quality are desired, which are capable, ultimately, of answering questions related to how much the quality of power is adequate to maintain appropriate performance and productivity of end-user equipment. Poor system quality levels on the other hand, imply either deficiency or excess in the overall system capabilities as designed by its planners, resulting in failure or malfunction of customer equipment and ultimately, dissatisfaction of the customer.

A single measurable index, designed by power quality factor PQF, is proposed in Munõz (2007) to reflect the overall system performance, taking into consideration different power quality aspects formulated previously and appropriate weighting factors $\omega_{1}$ that sum up to one. 


$$
P Q F=\omega_{1} R F D+\omega_{2} V T H D+\omega_{3} I T H D+\omega_{4} V U F+\omega_{5} I U F+\omega_{6} O C F
$$

The composite index gives a quick assessment of the power transfer quality at the selected point of the supply. An ideal PQF would be a factor equal to unity, on the other hand, a low value of $P Q F$ would indicate a high degree of power quality disturbances.

\section{Protective relays}

The last decades have seen enormous changes in relay technology, evolving from electromechanical, static, digital, to numerical relays. With the last generation of protection relays, these devices have become of great value in the evaluation of the power quality. In the following section the protective relays are described as well as the influence of the power quality on the relay performance. The test types performed on relays to evaluate the relay performance under prescribed voltage supply disturbances and the application of numerical relays for evaluating the power quality are also considered.

The selection of protective devices is based on the safety of personnel and equipment, and the quality and continuity of the electrical supply.

A protection relay is a device which by means of measuring power system quantities (currents and voltages) and processing them through its internal logic, has the capacity to control the operation of a circuit breaker. It is an important device for the safe and reliable operation of power systems.

In recent years, technological progress has led to the use of microprocessors in protective relay manufacture, resulting in the following:

- A significant increase in the amount of information that is processed by the relays.

- Easy calculation of electrical quantities such as for example harmonics.

- Secure and reliable exchange of digital information with remote locations.

- Continuous monitoring of protection relay integrity by self-supervision and autodiagnostics.

Historically, protection, control, oscillography and metering subsystems were comprised of separate devices, each designed with a specific purpose in mind. Today, protection, control, metering and a wide range of other tasks can be performed by a single item.

The numerical relays have revolutionized protection, control, non-revenue metering, oscillography and communication in power systems. Functional integration, protection multifunction, new methods of communication, reduced physical size, and a vast amount of available information are but a few of the benefits of this revolution.

A protective numerical relay can be explained as a collection of interacting specific purpose blocks (Fig. 1) as Central Processing Unit (CPU) with one or more DSP microprocessors, Memory (RAM, ROM and Flash NVRAM), Analog Inputs, Signal conditioning and Analog to Digital Conversion, Digital Inputs and their Conditioning, Outputs, Communication, Display and Keyboard (HMI), Real Time Clock, the Power Source, and software tools (Carbajal et al, 2009).

By using multiple microprocessors to provide the necessary computational performance, a large number of functions previously implemented in separate items of hardware can be included within a single item. Microprocessor-based protective relays perform, besides multi-protection functions (such as directional/non-directional overcurrent protection, distance protection, undervoltage protection, negative sequence current protection, reclosing, etc.), measurement of power system quantities (current, voltage, etc.), 
fault/event/disturbance recording, internal fault diagnosis, circuit-breaker monitoring (state, condition, control), voltage transformer supervision, and continuous self-monitoring in order to verify correct operation of most components within the device. Self-monitoring capabilities may include the alternating current (ac) signal inputs, analog measuring circuits, processors and memory for measurement, protection, data communications, trip circuit monitoring, and protection or data communications signals. For those conditions, failure of a self-monitoring routine generates an alarm and may inhibit operation to avoid false trips. Not all functions may be found in a particular relay, nevertheless, the protection relay no longer performs a basic protection function but is becoming an integral and major part within the overall network automation scheme.

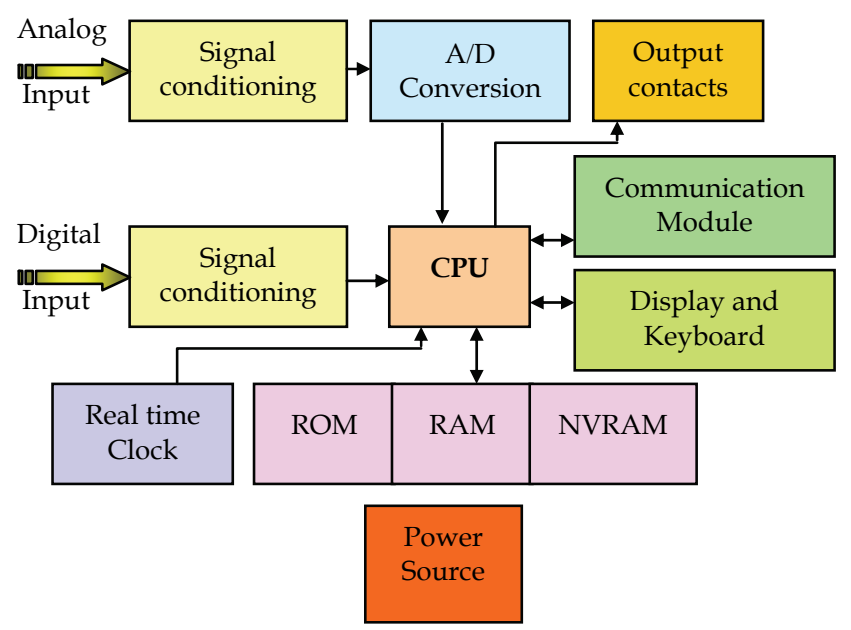

Fig. 1. Numerical relay architecture (Carbajal et alli, 2009)

The main difference between digital and conventional relays (electromechanical and solidstate relays) pertains to the method of input signal processing. In the case of numerical relays, input signals are converted into digital form within the analogue input system before being analysed by the processor. Numerical relays have their logic implemented in software and microprocessor technology.

The numerical relays are equipped with additional functions that have no direct relation with the protective elements but give an additional value to the system. Some of these are metering, monitoring, setting groups, fault record, communication and reports. The communication capability, not only with a center but also with each other, facilitates the deployment of overall-system wide protection and control philosophy. The advanced metering and communication protocol ports allow the relay to become a focal point in a SCADA system.

The numerical relays are hierarchically integrated to the digital system automation (DSA) of the power substations. They are at Level 1, as part of the positioning control unit (PCU), connected straight to the substation power equipment (Level 0). At Level 2, are the substation control unit (SCU) and the substation supervisory system (SCADA), which communicates with Level 3 in the Network Operation Center (NOC). 


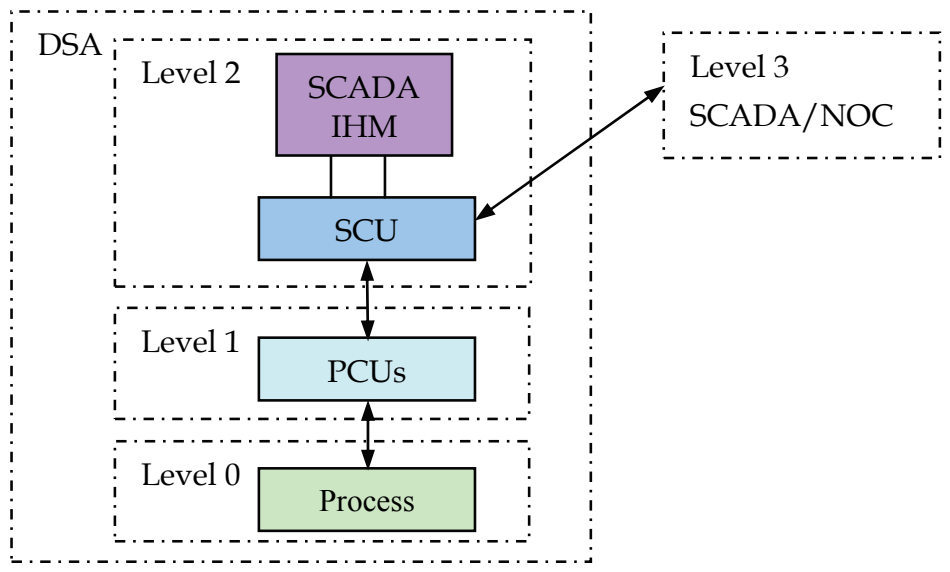

Fig. 2. Functional hierarchy of digital system automation of a power substation.

Although numerical relays are based on signal treatment, they are also affected by the power quality whereby their operation may be affected by disturbances and distortions in the waveform.

\subsection{The influence of power quality on protection relays}

Relays are exposed to disturbances in currents and voltages in various circumstances. Since the protection relays are required to operate correctly under abnormal system conditions, it is essential that their operation is guaranteed under such conditions (Cease and Kunsman, 2003), (Wang, 2003), (Zamora et al, 2004).

Protective relays are designed to operate when a fault in a power system occurs. However, non-fault voltage and current disturbances may lead to the inadvertent detection of a fault. Relay malfunctions, can result in a failure to trip for a fault condition and subsequently 'cascade' the event to an upstream protective device thus, affecting more customers. Equally a relay may trip when no fault is present which may also have a negative effect upon the customers.

The main steady-state disturbances that can affect the performance of protective relays are harmonics and frequency deviation. The reason why harmonics and frequency deviation are of concern, is that in case of distortion and/or frequency deviation, the reaction to a fault may become slower and the immunity from disturbances may decrease. The question is to what extent the harmonics and frequency deviation can affect the performance of protective relays (Wang, 2003).

The main negative influence that harmonic distortion of either voltages or currents can have on the digital relays, is that they can fail to trip under fault condition, or operate under a no fault condition. When measuring current and voltage, the relays must measure alone, the fundamental component of the signal. For this purpose, it is necessary to filter the harmonic and to calculate the rms value of the fundamental frequency only. The Fourier transform is the more used algorithm to filtrate the harmonic distortion (Cease and Kunsman, 2003).

Frequency variations can influence in the measurement ability of a digital relay and may include some distort in the measurement of some magnitude readings. The magnitude measurement of a relay (voltage, current) is based on making a sampling. This process has a defined number of samples (i.e. from 8 to 64), during one period. From this sampling, the 
rms value of the signal will be obtained. An error will occur if an increase or decrease of the frequency takes place and the sampling period of time is kept fixed whilst obtaining the rms. In order to achieve correct measurement, the relay needs to estimate power system frequency and must adjust the sampling rate to the network frequency regularly (Cease and Kunsman, 2003), (Zamora et al, 2004).

The main transient disturbances that can affect the performance of protective relays are due to component switching. Although component switching is a short duration disturbance, the relatively high deviations in voltages and currents are a potential threat to the correct operation of protective relays. Tripping, when no faults are present, is prevented in existing equipment by use of low-pass filters and verification intervals. However, this scheme will slow down the generation of a tripping signal in case of a fault (Wang, 2003).

One of the most visible power quality disturbances that have effect in the production sectors is the voltage sags. It almost always results from faults in the transmission and distribution systems, with widespread propagation over the power system. Voltage sags affect the measurements of other important power quality parameters. The power quality measurement standard IEC 61000-4-30 (2008) adopts a concept of flagging the voltage dips to take into consideration their influence on the measurements of power quality parameters. Voltage sags may affect the frequency measurements which may lead to frequency relay malfunction and to unexpected load shedding (Bronzeado, Zimath and Coser, 2008).

\subsection{Relaying tests}

To study the impact of power system disturbances on protective relays, it is necessary to apply some typical disturbances in protective relay testing. Tests based on IEC61000-4-7, IEC61000-4-15, IEC61000-4-11 and IEC60255-11 will be performed on multifunction numerical relays using a programmable ac/dc, one- and three-phase disturbance source. The relays responses will be presented.

\subsubsection{The influence of power quality of the supply voltage on the performance of a numerical relay}

To ensure consistent reliability and proper operation, protective relay equipment must be evaluated and tested. The purpose of testing protective relays is to ensure correct operation of the relay for all possible power system conditions and disturbances. The testing of protection relays may be divided into four stages: type tests, routine factory production tests, commissioning tests and periodic maintenance tests. Type tests are required to prove that a relay meets the published specification and complies with all relevant standards. Routine factory production tests are conducted to prove that relays are free from defects during manufacture. Testing will take place at several stages during manufacture. Commissioning tests are designed to prove that a particular protection scheme has been installed correctly, prior to setting to work. Periodic maintenance checks are required to identify equipment failures and degradation in service, so that corrective action can be taken.

The IEC 60255 - Part 11 (2008) specifies type testing on the auxiliary power supply of protective relays. The objective of the tests is to assess whether the protective relay will operate correctly when energized and subjected to voltage sags, voltage short interruptions, alternating components in dc (ripple), gradual shut-down/start-up test and polarity inversion. A programmable source is used to generate the disturbance types applied to the relays input power supplies. The test results are presented according to the acceptance criteria established in the international standard. 
The protective relays can be powered by either an a.c. or a d.c. power supply. The auxiliary supply can be supplied from a number of sources or safe supplies such as batteries, uninterruptible power supplies, generators, etc. When the energizing input is a d.c. power supply, the relays generally require a reliable source of d.c. power including measures to prevent damage to internal circuitry. Substation environments are particularly hostile to electronic circuits due to various, commonly found, forms of electrical interference such as switching operations and the effect of faults. The relays must be therefore immune to conducted and radiated interference from the electrically noisy substation environment. While it is possible to arrange for the dc supply to be generated from the measured quantities of the relay, this has the disadvantage of increasing the burden on the current transformers (CT) or voltage transformers (VT), and there will be a minimum primary current or voltage, below which the relay will not operate. This directly affects the possible sensitivity of the relay. So provision of an independent, highly reliable and secure source of relay power supply is an important consideration. To prevent mal-operation or destruction of electronic devices during faults or switching operations, sensitive circuitry is housed in a shielded case to exclude common mode and radiated interference. Since the protection relays are required to operate correctly under abnormal system conditions, it is essential that their operation is guaranteed under such conditions.

A numerical relay commonly found in the power distribution systems is used for testing both a.c. and d.c. auxiliary supplies. The type, levels and duration of tests according to IEC 60255-11 are given in Table 1.

\begin{tabular}{|c|c|c|}
\hline TYPE OF PHENOMENA & $\begin{array}{c}\text { TEST } \\
\text { SPECIFICATIONS }\end{array}$ & UNITS \\
\hline \multirow{3}{*}{$\begin{array}{c}\text { Voltage dips } \\
\text { (for dc power supply) }\end{array}$} & $\begin{array}{c}0 \\
10 \text { to } 1000\end{array}$ & $\begin{array}{l}\text { \% residual voltage } \\
\text { ms }\end{array}$ \\
\hline & $\begin{array}{c}40 \\
200\end{array}$ & $\begin{array}{l}\% \text { residual voltage } \\
\text { ms }\end{array}$ \\
\hline & $\begin{array}{c}70 \\
500\end{array}$ & $\begin{array}{l}\text { \% residual voltage } \\
\text { ms }\end{array}$ \\
\hline \multirow{3}{*}{$\begin{array}{c}\text { Voltage dips } \\
\text { (for ac power supply) }\end{array}$} & $\begin{array}{c}0 \\
0,5 \text { to } 25\end{array}$ & $\begin{array}{l}\% \text { residual voltage } \\
\text { cycles }\end{array}$ \\
\hline & $\begin{array}{c}40 \\
10 / 12 \text { at } 50 / 60 \mathrm{~Hz}\end{array}$ & $\begin{array}{c}\text { \% residual voltage } \\
\text { cycles }\end{array}$ \\
\hline & $\begin{array}{c}70 \\
25 / 30 \text { at } 50 / 60 \mathrm{~Hz}\end{array}$ & $\begin{array}{l}\% \text { residual voltage } \\
\text { cycles }\end{array}$ \\
\hline $\begin{array}{l}\text { Voltage interruptions } \\
\text { (for dc power supply) }\end{array}$ & $\begin{array}{l}0 \\
5 \\
\end{array}$ & $\begin{array}{l}\% \text { residual voltage } \\
\mathrm{s}\end{array}$ \\
\hline $\begin{array}{l}\text { Voltage interruptions } \\
\text { (for ac power supply) }\end{array}$ & $\begin{array}{c}0 \\
250 / 300 \text { at } 50 / 60 \mathrm{~Hz}\end{array}$ & $\begin{array}{l}\% \text { residual voltage } \\
\text { cycles }\end{array}$ \\
\hline $\begin{array}{l}\text { Alternating component in dc (ripple) } \\
\text { (for dc power supply) }\end{array}$ & $\begin{array}{c}15 \% \text { of rated de value } \\
100 / 120 \text { at } 50 / 60 \mathrm{~Hz}\end{array}$ & $\begin{array}{l}\mathrm{V} \mathrm{Hz} \text {, sinusoidal } \\
\text { waveform }\end{array}$ \\
\hline $\begin{array}{l}\text { Gradual shut-down/start-up } \\
\quad \text { (for dc power supply) }\end{array}$ & $\begin{array}{c}60 \\
5 \\
60\end{array}$ & $\begin{array}{l}\text { s, shut-down ramp } \\
\text { min, power off } \\
\text { s, start-up ramp }\end{array}$ \\
\hline Reversal of dc power supply polarity & 1 & $\min$ \\
\hline
\end{tabular}

Table 1. Type, level and duration of tests 
The disturbances should not cause any malfunction in the relay operation. Malfunctions include the operation of output relays and watchdog contacts, the resetting of microprocessors, alarm or trip indication, acceptance of corrupted data over the communication link and the corruption of stored data or settings. The voltage sag and voltage interruption tests are to determine the maximum time-length that a relay can withstand a sag/interruption in the auxiliary supply without de-energising and that when this time is exceeded whereby it does transiently switches off, that no misoperation occurs. The ac ripple superimposed on dc supply test determines that the relay is able to operate correctly with a superimposed ac voltage on the dc supply. This is caused by the station battery being charged by the battery charger.

The gradual shut-down/start-up test simulates a failed station battery charger, which would result in the auxiliary voltage to the relay slowly ramping down. The ramp up part simulates the battery being recharged after discharging. The relay must power up cleanly when the voltage is applied and it must not malfunction.

The criteria for acceptance are classified in two groups, A and C. The criterion A is related to the relay response to the a.c. and d.c. power supply voltages to $0 \%$ at specific time range and alternating component in d.c. for d.c. power supply. The criterion $\mathrm{C}$ in turn is related to the other types of phenomena as voltage sags other than to $0 \%$, voltage interruptions for a.c. and d.c. power supply, gradual shut-down/start-up for d.c. power supply and reversal of d.c. power supply polarity (IEC 60255-11, 2008). The effects of the tests should be assessed at the maximum and minimum values of the voltage according to the relay technical documentation.

\section{A. Test of voltage dip applied to the d.c. power supply}

Table 2 presents the test results for the applied dc voltage dips to $0 \%, 40 \%$ and $70 \%$ to the relay at the lowest and highest voltage operation range of Vmin $=87 \mathrm{Vdc}$ and Vmax $=300$ Vdc, respectively. Different time duration has been tested for voltage sag to $0 \%$.

\begin{tabular}{|c|c|c|c|}
\hline $\begin{array}{c}\text { DC voltage dip to } \\
(\%)\end{array}$ & $\begin{array}{c}\text { Test duration } \\
(\mathrm{ms})\end{array}$ & \multicolumn{2}{|c|}{ Test conclusion } \\
\cline { 3 - 4 } & 10 & Vmin & Vmax \\
\hline & 20 & Pass & Pass \\
& 30 & Pass & Pass \\
& 50 & Pass & Pass \\
& 100 & Pass & Pass \\
0 & 200 & Fail & Pass \\
& 300 & Fail & Pass \\
& 500 & Fail & Pass \\
& 1000 & Fail & Pass \\
\hline 40 & 200 & Fail & Pass \\
\hline 70 & 500 & Pass & Pass \\
\hline
\end{tabular}

Table 2. Voltage dip test applied to the d.c. energizing input.

For the lowest voltage, voltage sags to $0 \%$ with time duration exceeding $200 \mathrm{~ms}$ inclusive, has led the relay to a temporarily loss of function. The relay automatically switched-off resuming the functions at the end of the test, except its communication with the software that had to be manually re-established. 


\section{B. Test of voltage dip on the a.c. power supply}

Table 3 shows the test conclusion when the a.c. voltage dips to $0 \%, 40 \%$ and $70 \%$ has been applied to the relay ac power supply for the minimum and maximum voltage operation range of $80 \mathrm{Vac}$ and $265 \mathrm{Vac}$, respectively.

\begin{tabular}{|c|c|c|c|}
\hline $\begin{array}{c}\text { DC voltage dip to } \\
(\%)\end{array}$ & $\begin{array}{c}\text { Test duration } \\
\text { (cycles) }\end{array}$ & \multicolumn{2}{|c|}{ Test conclusion } \\
\cline { 3 - 4 } & 0.5 & Vmin & Vmax \\
\hline & 1 & Pass & Pass \\
& 2.5 & Pass & Pass \\
0 & 5 & Pass & Pass \\
& 10 & Pass & Pass \\
& 25 & Fail & Pass \\
\hline 40 & 12 & Pass & Pass \\
\hline 70 & 30 & Pass & Pass \\
\hline
\end{tabular}

Table 3. Voltage dip test applied to the a.c. energizing input.

The relay has failed, switching off when a voltage dip to $0 \%, 25$ cycles was applied for a reference a.c. voltage of $80 \mathrm{Vac}$. The relay has operated normally to the other conditions.

\section{Test of voltage interruption applied to the d.c. and a.c. power supplies}

Short voltage interruption of $5 \mathrm{~s}$ has been applied to the relay d.c. and of 300 cycles to the a.c. input, considering the lowest and the highest voltage operation range. The relay has failed during the test, showing no compliance to the standard.

\section{Ripple component test on the d.c. power supply}

A voltage ripple of $15 \%$ of the rated dc voltage, $120 \mathrm{~Hz}$ has been applied to the lowest (87 $\mathrm{Vdc})$ and to the highest ( $300 \mathrm{Vdc})$ d.c. voltage. The test has been successful.

\section{E. Gradual shut-down and start-up for d.c. power supply}

The IEC 60255-11 requires that a $60 \mathrm{~s}$ shut-down ramp and a $60 \mathrm{~s}$ start-up ramp with 5 min power off in between them, be applied to the d.c. power supply in order to observe the shutdown limit and the lowest start-up voltage. The test is applied to both the dc voltage operating limits, i.e., $\mathrm{Vmin}=87 \mathrm{Vdc}$ and $\mathrm{Vmax}=300 \mathrm{Vdc}$. The results are shown in Table 4 .

\begin{tabular}{|c|c|c|}
\hline DC VOLTAGE LIMIT & $\mathrm{V}_{\text {MIN }}(\mathrm{V})$ & $\mathrm{V}_{\mathrm{MAX}}(\mathrm{V})$ \\
\hline Shut-down & 63 & 63 \\
\hline Star-up & 81 & 85 \\
\hline
\end{tabular}

Table 4. Gradual shut-down and start-up test to the dc energizing input.

\section{F. Polarity inversion}

Reverse polarity for the power supply input has been applied for $1 \mathrm{~min}$. The relay has shown normal performance.

\subsection{Protection relays with power quality analysis function}

The importance of power quality assessment is ever increasing due to increased use of equipment and processes more susceptible to power system disturbances. As the power quality measurement process is a demanding one and power quality analyzers have 
developed into specialized, complex and expensive equipment, the modern numerical relays are able to measure and register values to power quality evaluation.

The protection relays are probably the only devices that are virtually mandatory on circuits of any significant rating, and as they have been equipped with advanced digital processing and statistical software, making them very similar in architecture to the power analyzers, they can to some extent to replace the power quality analyzers.

In order to evaluate the application of protective numerical relays to power quality assessment, two digital relays, named IED 1 and IED 2, with different characteristics and manufactures are investigated. The mass memory of the protective digital relays is, in general, small, with capacity to store only a few numbers of events. The number of events to be likely stored depends on the programmed number of cycles to be captured before and after the disturbance. The larger the estimated event duration, the lesser events will be stored. However, an on-line monitoring system can be applied to accomplish the recurring emptying of the relay mass memory.

The sampling rates of the IED 1 and IED 2 are 24 samples/cycle and 16 samples/cycle, respectively, and of the disturbance analyzer 128 samples/cycle for the programmed mode of operation. The resolution is 16 bits for both IEDs and the disturbance analyzer has 12 bits of resolution and $0.5 \%$ of accuracy.

Besides having a greater sampling rate, the IED 1 has larger storage capacity and it can store a larger number of events. Both IEDs have been programmed to capture up to 30 cycles or $500 \mathrm{~ms}$ in $60 \mathrm{~Hz}$ of events duration. IED 1 is able to capture voltage samples up to $1 \mathrm{~s}$ or 60 cycles per event, whilst IED 2 can capture, at most, 30 cycles per event. The number of prefault cycles to be captured can also be programmed, and it has been set to 5 cycles for both IEDs.

A programmable disturbance source has been used to apply the voltage disturbances to the relays and to a disturbance analyzer for comparison of the results. A threshold voltage equal to $0.9 \mathrm{pu}$ was used to trigger the relays and the disturbance analyzer. From the equipment databases the rms voltages based on (13) and the power quality indices $E_{v s}$ and $S_{e}$ based on (16) and (20) were calculated for different types and severities of voltage sags and short interruptions. The indices from the relays were compared to those calculated from the disturbance analyzer.

Three-phase and one-phase voltage sags and short-interruptions of $0.7 \mathrm{pu}$ and $0.0 \mathrm{pu}$, with duration of 3 and 20 cycles, were applied to the equipment under test following the recommendation of IEC 61000-4-11 (2001). In the following section, some test results are presented and error calculated for each considered event, taking into consideration the disturbance analyzer results as the reference.

\subsubsection{Voltage sag - Event 1}

Fig. 3 shows the rms voltage in pu versus time to IED 1, IED 2 and the disturbance analyzer to one-phase voltage sag to $0.7 \mathrm{pu}, 3$ cycles of duration. The voltage curves for all three equipment under test (EUT) do not show significant differences.

Table 5 presents the voltage sag magnitudes, durations and the $E_{V S}$ indices for the EUT. It can be seen from Table 5 that the voltage magnitude and the $E_{V S}$ errors of the IED 2 are larger than of the IED 1. Both IEDs have presented the same event duration measurement and therefore the same error. Furthermore, it can be observed that the voltage magnitude errors are larger than the event duration errors. 


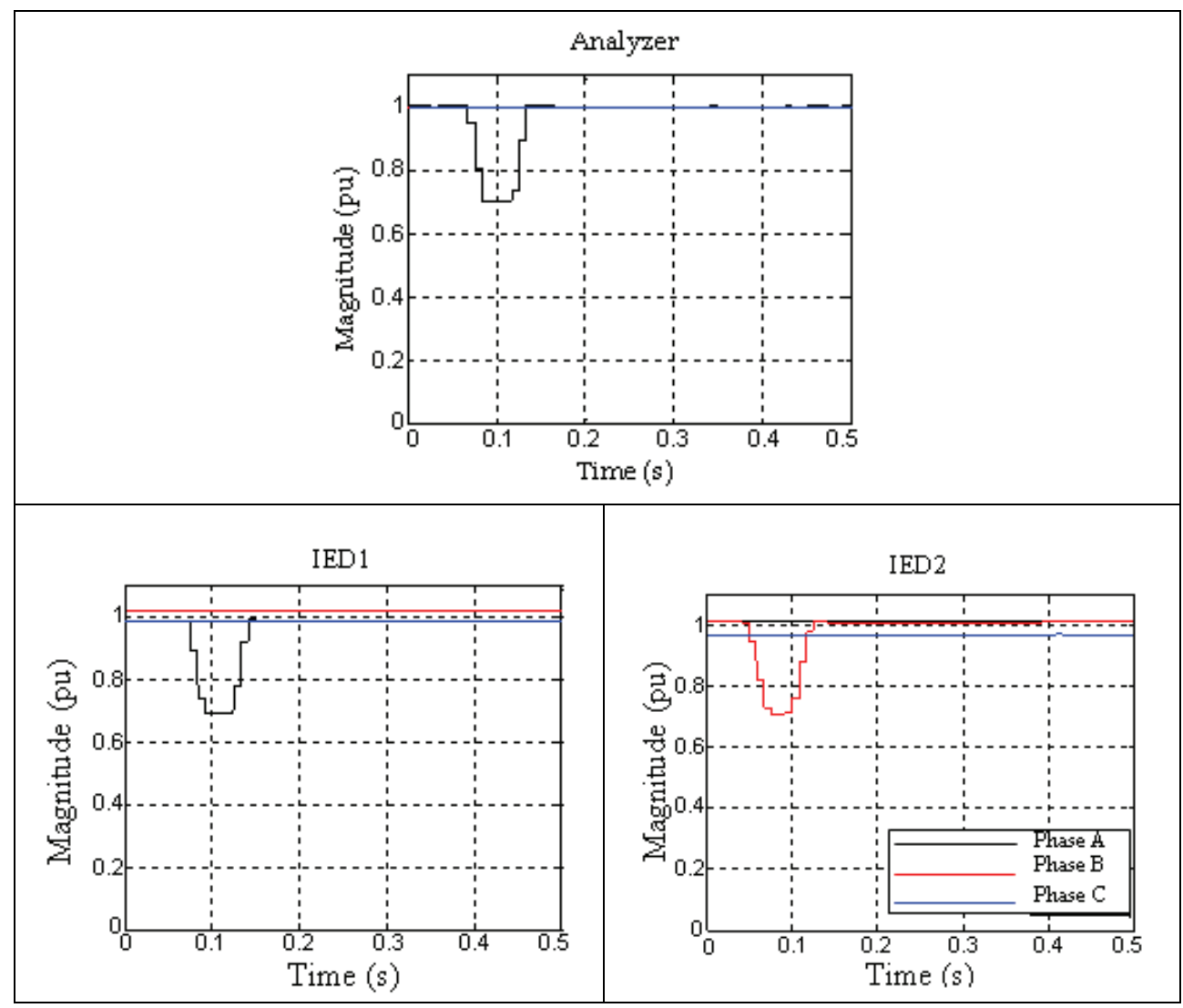

Fig. 3. RMS curve to voltage sag to $0.7 \mathrm{pu}, 3$ cycles.

\begin{tabular}{|l|c|c|c|c|c|}
\hline \multicolumn{7}{|c|}{ Event 1 } \\
\hline $\begin{array}{l}\text { Event } \\
\text { Characteristics }\end{array}$ & Analyzer & IED 1 & Error & IED 2 & Error \\
\cline { 2 - 6 } & Value & Value & Value & Value & Value \\
\hline Magnitude $(\mathrm{pu})$ & 0.7006 & 0.6931 & -0.0075 & 0.7093 & 0.0087 \\
\hline Duration $(\mathrm{s})$ & 0.0583 & 0.0582 & -0.0001 & 0.0582 & -0.0001 \\
\hline Evs $_{\text {(s) }}$ & 0.0297 & 0.0302 & 0.0005 & 0.0289 & -0.0008 \\
\hline
\end{tabular}

Table 5. One-phase Voltage Sag to: 0.7pu / 3 cycles.

\subsubsection{Voltage sag - Event 2}

The rms voltage curves to one-phase voltage sag to $0.7 \mathrm{pu}, 20$ cycles of duration for the EUT are depicted in Fig. 4. The voltage sag magnitudes and durations and the single-event indices $E_{V S}$ are given in Table 6.

From Table 6 it can be noticed that for a longer event of the same magnitude as the Event 1 the index $E_{V S}$ has increased. Although both IEDs have the same event duration measurement, the error for a longer event has increased. 


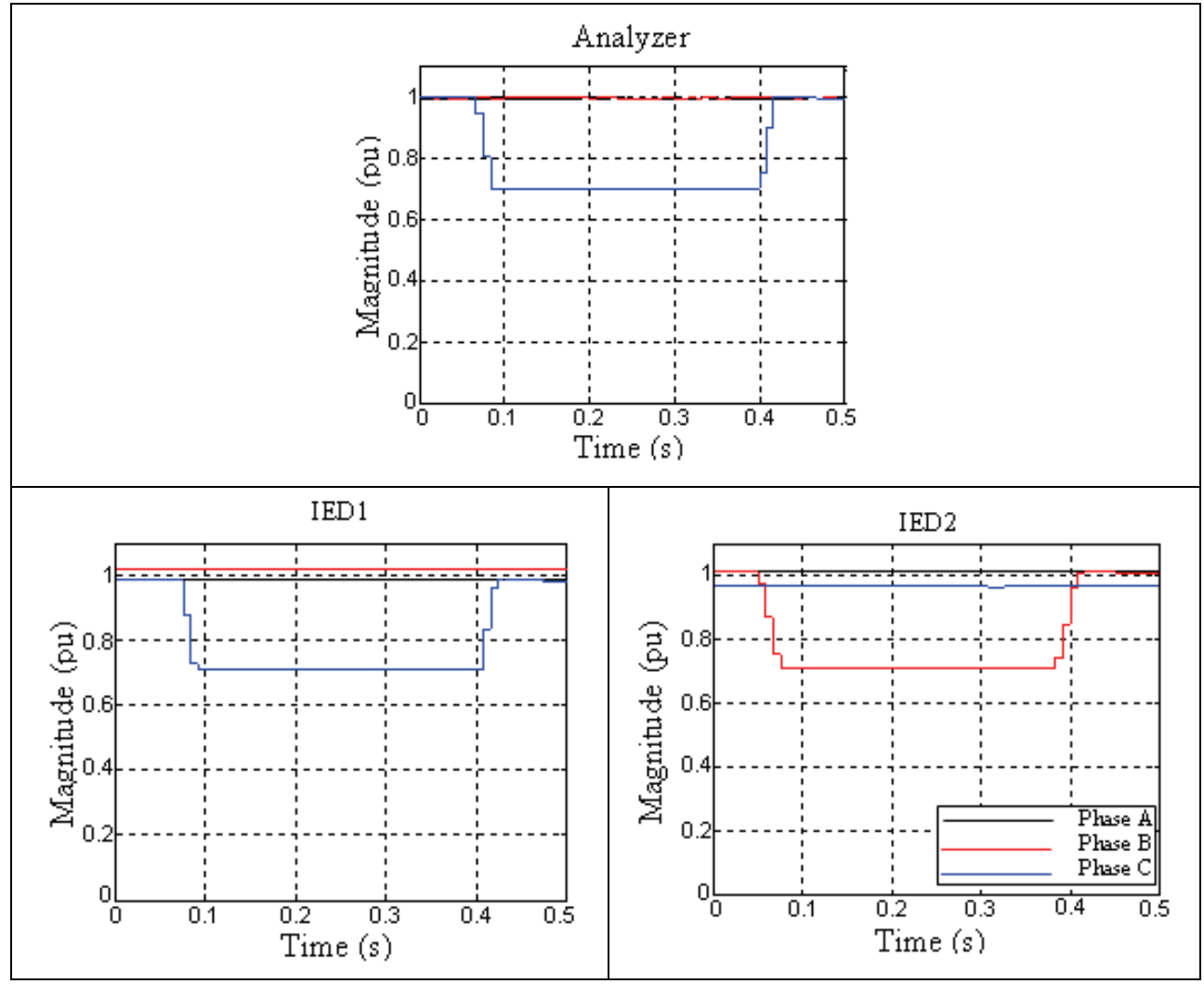

Fig. 4. RMS curves to voltage sag to $0.7 \mathrm{pu}, 20$ cycles.

\begin{tabular}{|l|c|c|c|c|c|}
\hline \multicolumn{7}{|c|}{ Event 2 } \\
\hline \multirow{2}{*}{ Event Characteristics } & Analyzer & \multicolumn{2}{|c|}{ IED 1 } & \multicolumn{2}{|c|}{ IED 2 } \\
\cline { 2 - 7 } & Value & Value & Error & Value & Error \\
\hline Magnitude $(\mathrm{pu})$ & 0.7012 & 0.7114 & 0.0102 & 0.7089 & 0.0077 \\
\hline Duration $(\mathrm{s})$ & 0.3333 & 0.3410 & 0.0077 & 0.3410 & 0.0077 \\
\hline$E_{V S}(\mathrm{~s})$ & 0.1694 & 0.1684 & -0.0010 & 0.1696 & 0.0002 \\
\hline
\end{tabular}

Table 6. One-phase Voltage Sag to: 0.7pu / 20 cycles.

\subsubsection{Short Interruption - Event 3}

The test results to one-phase 20 cycles short interruption are presented in Table 7 and the rms voltage curves are shown in Fig. 5.

From Table 7 it can be seen that the $E_{V S}$ indices have increased significantly reflecting, the event severity increasing. In comparison with the analyzer measurement, the errors from the relays measurement have increased when the event magnitude severity increased. 


\begin{tabular}{|l|c|c|c|c|c|}
\hline \multicolumn{7}{|c|}{ Event 3 } \\
\hline \multirow{2}{*}{ Event Characteristics } & Analyzer & \multicolumn{2}{|c|}{ IED 1 } & \multicolumn{2}{c|}{ IED 2 } \\
\cline { 2 - 6 } & Value & Value & Error & Value & Error \\
\hline Magnitude (pu) & 0.0593 & 0.0036 & -0.0557 & 0.0000 & -0.0593 \\
\hline Duration (s) & 0.5083 & 0.4491 & -0.0592 & 0.4408 & -0.0675 \\
\hline$E_{V S}(s)$ & 0.5065 & 0.4491 & -0.0574 & 0.4408 & -0.0657 \\
\hline
\end{tabular}

Table 7. One-phase short Interruption: 0.0pu / 20 Cycles.

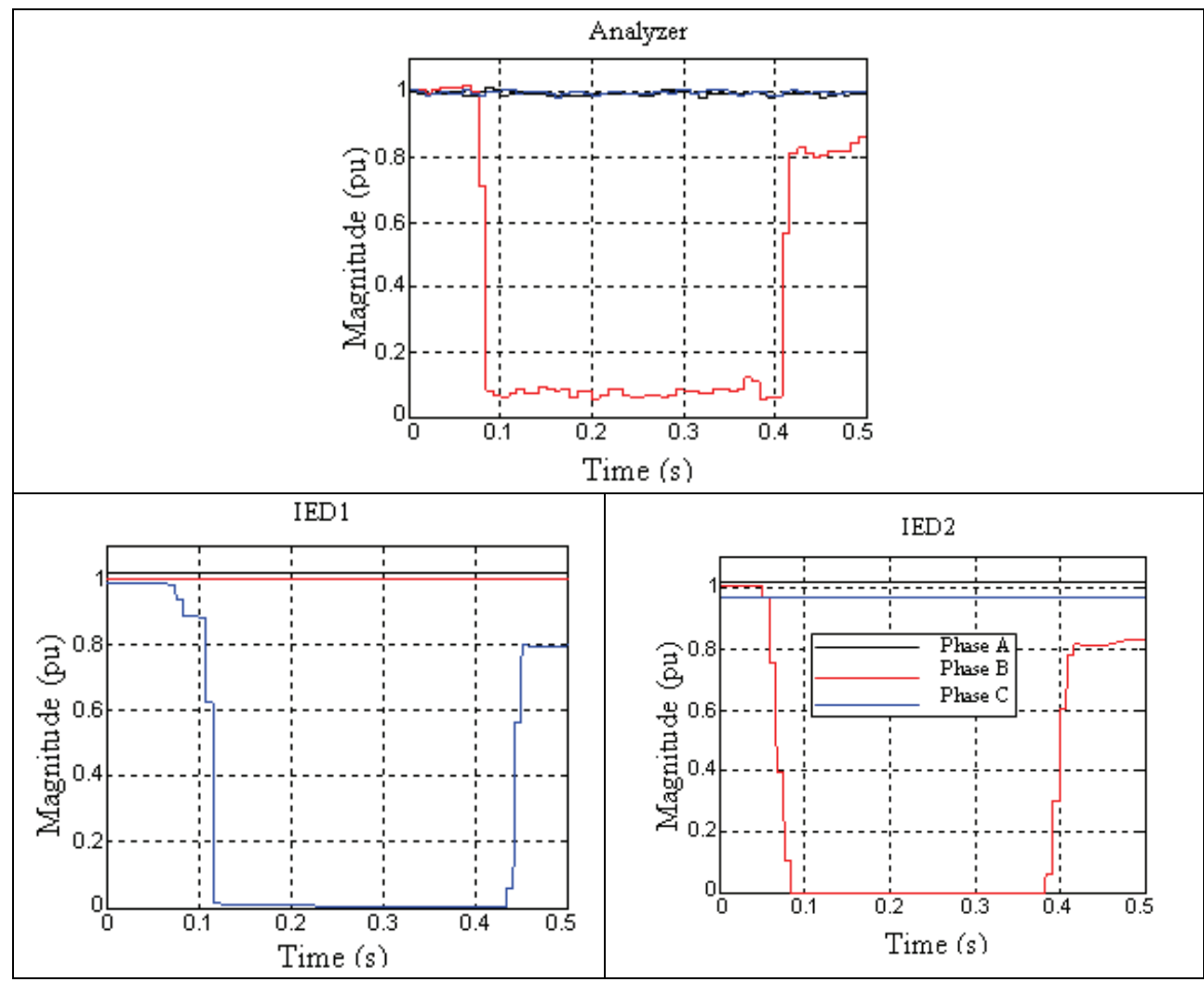

Fig. 5. RMS Voltage to one-phase 20 cycles short interruption.

\subsubsection{Event severity index $S_{e}-$ Event 4}

The event-severity indices $S_{e}$ based on the algorithm presented in Table 1 when calculated to the three events previously described are shown in Table 8.

It can be noted that for event 3 , the $S_{e}$ indices is greater than 1 for all the EUT, which denotes that the event severity is under the SEMI low voltage ride-through curve. In contrast, the indices $S_{e}$ are smaller than 1 for events 1 and 2, indicating that the SEMI low voltage ridethrough curve has not been violated and that the event characteristics are in the normal 
operating region of the SEMI curve as pointed out in Fig. 6. It is worth observing that each time interval of the SEMI curve corresponds to a different event-severity scale, and as a result the $S_{e}$ ordinate scale is not shown in Fig. 6.

\begin{tabular}{|c|c|c|c|c|c|}
\hline \multirow{2}{*}{ Event } & Analyzer & \multicolumn{2}{|c|}{ IED 1 } & \multicolumn{2}{c|}{ IED 2 } \\
\cline { 2 - 6 } & Value & Value & Error & Value & Error \\
\hline 1 & 0.5987 & 0.6137 & 0.0150 & 0.5814 & -0.0173 \\
\hline 2 & 0.9959 & 0.9619 & -0.0340 & 0.9705 & -0.0254 \\
\hline 3 & 3.1043 & 3.2881 & 0.1838 & 3.3000 & 0.1957 \\
\hline
\end{tabular}

Table 8. Event-severity Index Se.

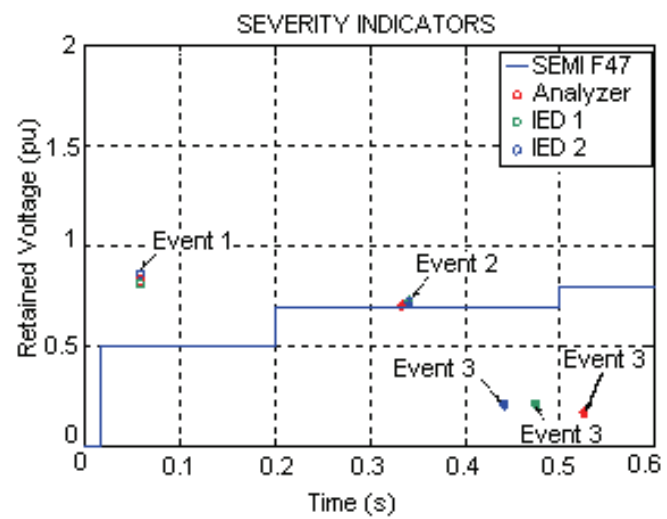

Fig. 6. SEMI curve and the Severity indicators

\section{The last development on Wide Area Monitoring, Protection and Control}

For improving power system security and performance, new emerging technologies in the area of Wide Area Monitoring, Protection and Control concepts (WAMPC) have been recently proposed. Technological advancements in measuring and communicating time synchronized real-time power system parameters, through highly secure high-speed telecommunication networks, provide opportunities for implementing intelligent protection and control schemes with advance warning mechanisms.

Conventional protection devices are designed to protect individual assets in a power system, for which locally measured values are usually sufficient. In contrast, network control systems with a system-wide view of the processes within the power system require dynamic information about power flows and the phase angles of the electrical quantities at various network nodes in order to safeguard the power system stability. The measurement data can be provided by phasor measurement units (PMU) and open up new fields of application for network control under the concept of Wide Area Monitoring Protection \& Control (WAMPC).

Phasor Measurement Units (PMU) have revolutionized the way state estimation is being performed. Their unique ability to measure the voltage and current phasors (magnitude and phase angle) with very high accuracy makes them extremely useful in modern day energy management systems. 


\section{Conclusions}

The quality of the voltage supply is a common concern of the power utilities and customers. The importance of power quality assessment is ever increasing due to increased use of equipment and processes more susceptible to power system disturbances.

Power quality analyzers available in the market are expensive and specialized to be applied on a mass scale. The protection relays are devices that are mandatory on circuits of any significant rating. As they have been equipped with advanced digital processing and statistical software making them very similar in architecture to the power analyzers, they can to some extent, replace the power quality analyzers. Besides the multi functionality of the digital relays, they can additionally contribute to the power quality evaluation of the power system, saving investments in power analyzers.

As a digital technology based device, the protective relays can be sensitive to power quality variations. Performing tests on protection relays is a required practice in order to evaluate the relay performance and characteristics, and to certify the equipment compliance to the requirements of technical standards. The numerical relays perform many functions besides protection which ought to be accurate and promptly operate whenever required. The sensitivity and the immunity of the relays are evaluated through tests performed according to international standards like IEC 60255-11, IEC 61000-4-11, IEC 61000-4-7 and IEC 61000-415. Results of tests performed in a well known relay trade name relay when it's a.c. and d.c. power supply are energized and subjected to voltage sags, interruptions, alternating components and gradual shut-down and start-up have shown that the relay failed under d.c. voltage sag and d.c. and a.c. short voltage interruption.

The modern multifunction digital relays are able to measure and register values useful to the power quality assessment. Power providers are building databases to assess utility service quality performance indicators. The widespread use of digital relays can assist in achieving this task. Feasible indices are needed to address the security, quality, reliability and availability of the power system. Tests performed using two numerical relays and a disturbance analyzer have proved that the relays database can be used to calculate indices to identify the severity of disturbances and to evaluate the quality of the site and the system. Indices have been used based on both magnitude and duration of short-duration voltage variation in all three phases. The least rms voltage over the event duration has been used to calculate the index of energy $\left(E_{V S}\right)$ and the event severity index $\left(S_{e}\right)$.

Performance indices calculated from the database of two digital relays with sampling rates of 24 and 16 samples per cycle and resolution of 16 bits have been compared to indices calculated from a disturbance analyzer of 128 samples per cycle and resolution of 12 bits. The digital relay IED 1 with 24 sampling rate has presented smaller errors to all events tested. The digital relays have captured correctly all the considered events. As the voltage sag and short interruptions are power frequency events the frequency samplings of the IEDs have proven to be suitable.

\section{References}

Albert, H.; Golovanov, N.; Kot, A. and Brozek, J. (2008). Frequency Variation. Handbook of Power Quality. John Wiley \& Sons. Ltd. Edited by Baggini, A. ISBN 978-0-470-065617, England.

Bollen, M. H. J.; Sabin, D. D. and Thallam, R. S. (2003). Voltage-sag indices- recent developments in IEEE P1564 Task Force. Invited paper presented at the joint 
symposium CIGRE/IEEE-PES on "Quality and Security of Electric Power Delivery Systems", Montreal, 7-10 October 2003.

Brozeado, H. S.; Zimath, S. L. and Coser, J. (2008). Effect of Voltage Dips on Frequency Relays: Case Study of Power Quality Improvements in a Petrochemical Plant. International Conference on Harmonics and Quality of Power - ICHQP, pp.1-5, Autralia, October 2008, Wollongong.

Carvajal, I. O.; Sedano, E. C. and Jiménez, B. A. R. (2009). An Electric Energy Distribution Systems Protection Microprocessor Based Relay, 52nd IEEE International Midwest Symposium on Circuits and Systems, ISBN: 978-1-4244-4479-3, Mexico, August 2009, Cancun.

Cease, T. W. and Kunsman, S. A. (2003). Protective Relaying and Power Quality. IEEE PSRC Working Group Report.

Colaço, A. L. G.; Melo, N. X.; Leão, R. P. S.; Barroso, G. B.; Sampaio, R. F. and Ciarlini, R. C. (2008). Power Quality Assessment and the Application of Protective Relays, International Conference on Harmonics and Quality of Power - ICHQP, pp.492-498, Autralia, October 2008, Wollongong.

Duncan, B. K. and Bailey, B.G. (2004). Protection, metering, monitoring, and control of medium-voltage power systems, IEEE Transactions on Industry Applications, vol. 40, no. 1, pp. 33 - 40, Jan./Feb. 2004.

Gosbell, G. V. (2002). Power Quality Monitoring - Plant Investigations, Technical Note No.5, Integral Energy Power Quality Centre, University of Wollongong, January 2002.

IEC 61000-4-11 Testing and Measurement Techniques - Voltage Dips, Short Interruptions and Voltage Variations Immunity Tests. Edition 1.1 2001-03.

IEC 61000-4-30 Testing and measurement techniques - Power quality measurement methods. Edition 2.0 2008-10, ISBN 2-8318-1002-0, 134pp.

IEC 61255-11 Measuring Relays and Protection Equipment - Voltage dips, short interruptions, variations and ripple on auxiliary power supply port. Edition 2.0 2008-10. ISBN 2-83181003-9, 26pp.

IEEE 1159 Recommended Practice for Monitoring Electric Power Quality, 1995, ISBN 1-55937-5493, 76pp.

Mackrell, A.; Fantana, N.; Steingräber, W.; Kopejtková, D.; Ravetta, C.; Jung, T.; Schumacher, M.; Anguas J.; Ford, G.; Woodcook, D.; Müller, L.; Moore, P.; Mercier, A.; and Skog, J. (2010). Obtaining Value form On-line Substation Condition Monitoring. Electra, No.249, April 2010, pp. (21-25), ISSN 1286-1146.

Munõz, A. M-. (2007). Power quality: mitigation technologies in a distributed environment, Springer, ISBN 9781846287718.

Thallam, R.S. and Heydt G. T. (2000). Power Acceptability and Voltage Sag Indices in the Three Phase Sense. IEEE Proc. PES Summer Meeting, 16-20 July 2000, Seattle WA, USA, pp. 905-910.

Zamora, I.; Mazón, A. J.; Valverde, V.; Torres, E. and Dyśko, A. (2004). Power Quality and Digital Protection Relays, International Conference on Renewable and Power Quality - ICREPQ 2004, pp.1-8, Barcelona, Spain, April 2004. 


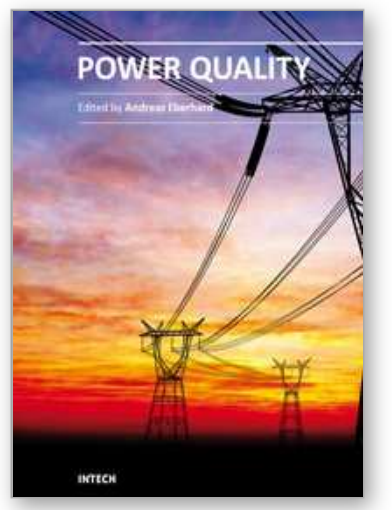

\author{
Power Quality \\ Edited by Mr Andreas Eberhard
}

ISBN 978-953-307-180-0

Hard cover, 362 pages

Publisher InTech

Published online 11, April, 2011

Published in print edition April, 2011

Almost all experts are in agreement - although we will see an improvement in metering and control of the power flow, Power Quality will suffer. This book will give an overview of how power quality might impact our lives today and tomorrow, introduce new ways to monitor power quality and inform us about interesting possibilities to mitigate power quality problems.

\title{
How to reference
}

In order to correctly reference this scholarly work, feel free to copy and paste the following:

Ruth P.S. Leao, Giovanni C. Barroso, Nelber X. Melo, Raimundo F. Sampaio, Janaîna A. Barbosa and Fernando L.M. Antunes (2011). Numerical Relay: Influenced by and Accessing the Power Quality, Power Quality, Mr Andreas Eberhard (Ed.), ISBN: 978-953-307-180-0, InTech, Available from: http://www.intechopen.com/books/power-quality/numerical-relay-influenced-by-and-accessing-the-powerquality

\section{INTECH}

open science | open minds

\section{InTech Europe}

University Campus STeP Ri

Slavka Krautzeka 83/A

51000 Rijeka, Croatia

Phone: +385 (51) 770447

Fax: +385 (51) 686166

www.intechopen.com

\section{InTech China}

Unit 405, Office Block, Hotel Equatorial Shanghai

No.65, Yan An Road (West), Shanghai, 200040, China

中国上海市延安西路65号上海国际贵都大饭店办公楼405单元

Phone: +86-21-62489820

Fax: +86-21-62489821 
(C) 2011 The Author(s). Licensee IntechOpen. This chapter is distributed under the terms of the Creative Commons Attribution-NonCommercialShareAlike-3.0 License, which permits use, distribution and reproduction for non-commercial purposes, provided the original is properly cited and derivative works building on this content are distributed under the same license. 